\title{
Performance evaluation of websites using entropy and grey relational analysis methods: The case of airline companies
}

\author{
Kemal Vatansever ${ }^{\mathrm{a}^{*}}$ and Yakup Akgül ${ }^{\mathrm{b}}$
}

${ }^{a}$ Department of Business, Alanya Alaaddin Keykubat University, Antalya, Turkey

${ }^{b}$ Department of International Trade, Alanya Alaaddin Keykubat University, Antalya, Turkey

\begin{tabular}{l}
\hline C H R O N I C L E \\
\hline Article history: \\
Received January 16, 2017 \\
Received in revised format: \\
May 22, 2017 \\
Accepted June 23, 2017 \\
Available online \\
June 23, 2017 \\
\hline Keywords: \\
Website performance \\
Entropy weight method \\
Grey relational analysis
\end{tabular}

\section{Introduction}

Lately, we have become witness to a crucial alteration of our lives to a global community with the onset of the internet era. The web is an increasingly more vital asset in many sides of life: government, education, commerce and more. Due to the internet and e-commerce spread out, many airline companies are striving to arouse customers to shift from Word of Mouth to the Word of Web. The web site of an airline company is an imperative factor of their operations and future developments. Most of airlines supply ticketing facilities, booking a flight, planning a route and flight information via their web sites. Hence, the websites of airlines have become an indispensable part of business processing and are being leveraged to reinforce the efficiency and effectiveness of the business, and to gain 
competitive advantage in the rigid competition environment. Utilizing the web devices many airlines have been able to raise their being customer-focused and their attributes of products and services. The quality of website is now regarded as a crucial aspect in attracting the customers' attention. Particularly in air transportation industry, the favor of the internet and e-commerce technologies makes it necessary to enhance the quality of airlines websites to accomplish more market share and struggle with other companies in this area. It is compulsory for companies to know how good their websites are in order to be more successful in their businesses. Most of airline companies now have constituted devoted websites to complement their business activities and to tender their services, but it is likely that a importantly larger ratio has no clear knowledge of how successful their sites are or how many gaps should be filled between the status quo and an ideal e-commerce website. However, they may not be aware about the quality of their websites or the gaps which should be considered to be an ideal ecommerce website (Lee \& Kozar, 2006; Phippen et al., 2004). Put it differently, how much struggle must the airlines put into developing the websites in order to carry out their coveted levels? This raises the crucial subject of how airlines can impressively ascertain the attributes of e-commerce websites. Due to the multi dimensional attributes of the website development in this context, it must be properly tended by the multi criteria decision making (MCDM) methods. Recently, there is no codified model for appraising airline websites, and the existing methods do not provide enough understanding for airlines' proprietors to ascertain whether their websites meet the recognized guidelines from the attribute of "website quality" (Tsai et al., 2011).

We are inspired by the absence of such an overall website assessment model which reckon the qualitative criteria from the customer's standpoint for airline websites. In our recommended model, website effectiveness was examined under the consideration of the realistic criteria which were ascertained in the previous studies with extended form.

By suggesting comprehensive measurements based on standpoint of "web site quality", the recommended model can contribute the valuable information for airlines' owners to understand the relative level of competitive of their websites in the air transportation industry.

The main aim of the study is to establish a performance assessment model for airlines' websites, and to prioritize enhancement processes in order to best allocate the convenient assets for the web site quality. To attain that, a model is aimed that integrates Grey Relational Analysis and Entropy Weight Method for evaluating airlines' websites performance companies which operate in Turkey. Airline tickets are one of the most popular items purchased via firm websites, the importance of the study reveals that decision support will be provided to decision makers. In this direction, first of all, related website evaluation literature is mentioned. Then, the website performance for evaluation is described which is used in the methodology. Finally, the weights of the attributes of the 11 airline websites were calculated by the Entropy Weight Method, the evaluation of the alternatives using Grey Relational Analysis method were given ranking of websites as an integrated two-stages multi-criteria decisionmaking techniques and suggestions were made to the decision makers.

\section{Literature review}

In the literature, many website evaluation studies can be faced including the evaluation of airline web site quality and airline service quality. In this paper, more specifically, airline website evaluation is focused on. It is realized that statistical and decision making methods such as Decision Making Trial and Evaluation Laboratory- DEMATEL (Fontela \& Gabus, 1976), Analytic Hierarchy Process- AHP (Saaty, 1980), Analytic Network Process- ANP (Saaty, 1996), VlseKriterijumska Optimizacija I Kompromisno Resenje- VIKOR (Opricovic \& Tzeng, 2004), Fuzzy Analytical Hierarchy Process (Chang, 1996) often have been used for the airline website evaluation. 
Hidalgo et al. (2007) presented a quality evaluation model of airline web sites which was based on a fuzzy linguistic approach. Jati (2009) tested the Asian flag carrier airlines via online web diagnostic tools to assess the quality of the website. Author proposed a methodology for ascertaining and quantifying the best airlines websites based on many criteria of website quality by using AHP. In addtion, the same year, Tsai et al. (2009) proposed an integrated model for evaluating the airlines' websites in terms of the perspectives of "marketing mix 4Ps" and "website quality". The DEMATEL, the ANP and the modified VIKOR methods were used for evaluating airlines' websites. Tsai et al. (2011) introduced a combined model for assessing the airlines' websites functionality. The proposed model was based on the attitudes of "marketing mix 4Ps" and "website quality", in which the criteria analyzed via DEMATEL method, and then the weight of each criterion was calculated by ANP, finally the modified VIKOR method ranked the performance of the websites.

Dominic and Jati (2011) tested the Asian airlines websites to evaluate the quality of the tested websites by using the online web diagnostic tools. Researchers proposed an assessment model for ascertaining and appraising the best airlines website based on many criteria of the website quality, which combines the linear weightage model (LWM), AHP, fuzzy analytical hierarchy process (FAHP) and one new hybrid model (NHM). Khan and Dominic (2013) aimed to check the Asian airlines website quality via online web diagnostic tools. The analytical hierarchy process (AHP) was used to evaluate the website quality of each airline and the results suggested the best airline operates in Malaysia.

As indicated above, the previous works have neglected to supply an extensive and systematic attitude that quantitatively assessment a website's overall performance, and their research models must be enhanced. Distinct web site quality criterion is not always entirely independent in reality (Wu \& Lee, 2007). For that reason, this study integrates Grey Relational Analysis method and Entropy Weight Method to handle the interdependence between criteria instead of adopting individual approach. The Entropy Weight Method calculated the weights of criteria, which were integrated with the Grey Relational Analysis method to calculate the extensive performance variance rate of each website Entropy Weight Method can only acquire the ranking of websites. The presented model overwhelms the obstacles of the prior works and proposes enough insights for implanters to precisely appraise the present level of their websites according to the critical criteria that regulates their competitive advantages.

\section{Methodology}

This study aims to test and to measure the both Turkish flag carrier airlines website and not flag carrier Turkish airlines website quality via online web diagnostic tools. The proposed model is applied to analyze the websites of 11 air transportation companies for determining and evaluating the best airlines websites based on many criteria of website quality in Turkey. The eleven selected airline websites are: Turkish Airlines, Pegasus Airlines, Onur Airlines, SunExpress Airlines, Sky Airlines, Corendon Airlines, Freebird Airlines, İzair Airlines, Tailwind Airlines, Borajet Airlines and Anadolujet Airlines.

In the study, first of all, performance criteria have been determined by experts. The weights of the criteria were calculated by Entropy Weight Method and then the performance rankings of the websites were taken the alternatives via Grey Relational Analysis method. The Methodological framework of the study is shown in Fig. 1. 


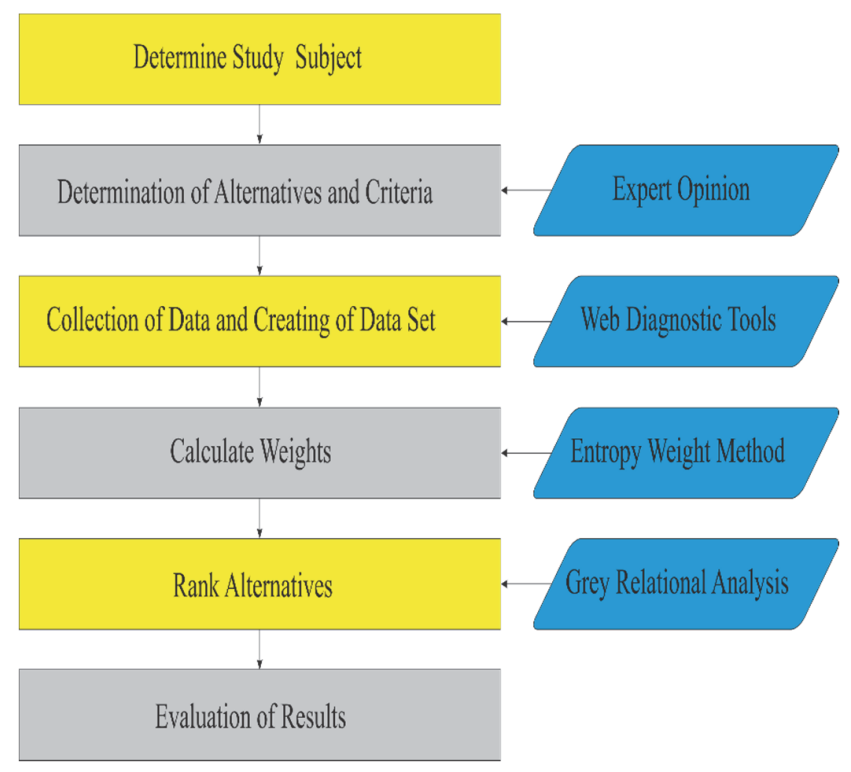

Fig. 1. Methodological Framework

\subsection{Entropy Weight Method}

Decision makers choose from the alternatives in multi-criteria decision-making problems. Decision makers must be taken into consideration criteria which affect the alternatives when making this choice. There are many criteria that influence this decision in the selection process of any alternatives and each of these criteria in different severity levels are effective over alternatives. AHP and expert opinions as subjective evaluation methods are used to determine the weight of the criteria. Criteria are categorized according to expertss opinion that is diffucult, since generalisation cannot be made clearly and the objective assessment methods should be used in case of the deficiency of pairwise comparisons. Shannon is firstly introduced Information entropy in his paper of "A Mathematical Theory of Communications", which is a measure of uncertainty, then it has been broadly used in many areas such as engineering, management and so on (Wu et al., 2011). The entropy by Shannon, can be used to ascertain the disorder degree and its utility in system information. The smaller the entropy value is, the smaller the disorder degree of the system is. The index's weight is determined by the amount of information based on Entropy Weight Method, which is one of objective fixed weight methods (Li et al., 2011).

Entropy Weight Method includes following 5 steps (Deng et al., 2000; Shemshadi et al., 2011):

Step 1: Construction of a decision matrix (X). A set of alternatives $\left(A=\left\{A_{i}, i=1,2, \ldots, n\right\}\right)$ is to be compared to with respect to a set of criteria $\left(C=\left\{C_{j}, j=1,2, \ldots, m\right\}\right)$. Therefore, an $\mathrm{n} \times \mathrm{m}$ performance matrix (the decision matrix; $\mathrm{X}$ ) can be obtained as:

$$
X=\left[\begin{array}{cccc}
x_{11} & x_{12} & \ldots \ldots & x_{1 m} \\
x_{21} & x_{22} & \ldots \ldots & x_{2 m} \\
\ldots . . & \ldots . . & \ldots \ldots & \ldots \ldots \\
x_{n 1} & x_{n 2} & \ldots \ldots & x_{n m}
\end{array}\right]
$$

where $x_{i j}$ is a crisp value indicating the performance rating of each alternative $A_{i}$ with regard to each criterion $C_{j}$. 
Step 2: To ascertain objective weights by the entropy measure, the decision matrix in Eq. (1) needs to be normalized for each criterion $C_{j}(j=1,2, \ldots, m)$ as

$$
p_{i j}=\frac{x_{i j}}{\sum_{p=1}^{n} x_{p j}}, i=1,2, \ldots, n
$$

The Normalized decision matrix is obtained as a result of the process.

$$
P=\left[\begin{array}{cccc}
p_{11} & p_{12} & \cdots \cdots & p_{1 m} \\
p_{21} & p_{22} & \cdots \cdots & p_{2 m} \\
\cdots \cdots & \cdots \cdots & \cdots \cdots & \cdots \cdots \\
p_{n 1} & p_{n 2} & \cdots \cdots & p_{n m}
\end{array}\right]
$$

Step 3: Calculate the entropy measure of every index using the following equation:

$$
e_{j}=-k \sum_{i=1}^{n} p_{i j} \ln p_{i j}
$$

where $k=\frac{1}{\ln (n)}$ is a constant which guarantees $0 \leq e_{j} \leq 1$.

Step 4: The degree of divergence $\left(d_{j}\right)$ of the average intrinsic information contained by each criterion $C_{j}(j=1,2, \ldots, m)$ can be calculated as

$$
d_{j}=1-e_{j}
$$

the more $d_{j}$ is, the more important the criterion $j$ th is.

Step 5: The objective weight for each criterion $C_{j}(j=1,2, \ldots, m)$ is thus given by

$$
w_{j}=\frac{d_{j}}{\sum_{j} d_{j}}
$$

\subsection{Grey Relational Analysis}

Ju-Iong Deng formulated the grey system theory in 1982. A White system is specified when the internal message such as architecture, operation mechanism, system characteristics and parameters are completely known. Contrarily, if one cannot acquire any information and characteristics about the system, then it is a black system. The primary description of greyness is information being incomplete or unknown, thus an element from the incomplete message is adopted as grey elements. Grey Relation Analysis method measures the relations among the factors, and its definitions in mathematics (Wang, 2008; Lu et al., 2008). Grey Relational Analysis is broadly applied in evaluating or judging the performance of a complex project with meager information (Sentilkumar et al., 2014). More specifically, traditional grey relational analysis includes the following six steps (Zhai et al., 2009; Wu, 2002):

Step 1: Construction of an initial decision matrix (X). Assuming that there are $n$ data sequences characterized by $m$ criteria,

$$
X=\left[\begin{array}{llll}
x_{1}(1) & x_{1}(2) & \ldots \ldots & x_{1}(m) \\
x_{2}(1) & x_{2}(2) & \ldots \ldots . & x_{2}(m) \\
\ldots \ldots & \ldots \ldots \ldots & \ldots \ldots & \ldots \ldots \ldots \\
x_{n}(1) & x_{n}(2) & \ldots \ldots . & x_{n}(m)
\end{array}\right]
$$


where $x_{i}(j)$ is the entity in the $i$ th data sequence corresponding to the $j$ th criterion.

Step 2: Normalize the data set. Data can be used by one of the three types. Larger is better, smaller is better and nominal is best.

Larger is better

$$
x_{i}^{*}(j)=\frac{x_{i}(j)-\min _{i=1}^{n}\left[x_{i}(j)\right]}{\max _{i=1}^{n}\left[x_{i}(j)\right]-\min _{i=1}^{n}\left[x_{i}(j)\right]}
$$

Smaller is better

$$
x_{i}^{-}(j)=\frac{\max _{i=1}^{n}\left[x_{i}(j)\right]-x_{i}(j)}{\max _{i=1}^{n}\left[x_{i}(j)\right]-\min _{i=1}^{n}\left[x_{i}(j)\right]} .
$$

Nominal is best

$$
x_{i}^{0}(j)=1-\frac{\left|x_{i}(j)-x_{o b j}(j)\right|}{\max \left\{\max _{i=1}^{n}\left[x_{i}(j)\right]-x_{o b j}(j), x_{o b j}(j)-\min _{i=1}^{n}\left[x_{i}(j)\right]\right.},
$$

where $x_{o b j}(j)$ is the target value for the $j$ th criterion, and $\min _{i=1}^{n}\left[x_{i}(j)\right] \leq x_{o b j}(j) \leq \max _{i=1}^{n}\left[x_{i}(j)\right]$ Normalization process is completed with the aid of the above equations.

Step 3: Construct the normalized matrix and generate the reference sequence based on Eqs. (8-10) Normalized Matrix

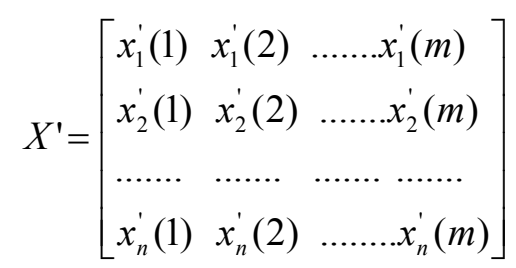

Reference Sequence $\quad X_{0}^{\prime}=x_{0}^{\prime}(1), \quad x_{0}^{\prime}(2), \quad \ldots . ., \quad x_{0}^{\prime}(m)$

where $x_{0}^{\prime}(j)$ is the reference value in relation to the $j$ th criterion and is determined by the largest normalized value of each criterion.

$x_{0}^{\prime}(j)=\max _{i=1}^{n}\left[x_{i}^{\prime}(j)\right]$

Step 4: The distance between the normalized value with reference criteria series, measured in an absolute way and absolute value matrix is generated.

$$
\begin{aligned}
& \Delta_{o i}(j)=\left|x_{o}^{\prime}(j)-x_{i}^{\prime}(j)\right| \\
& \Delta=\left[\begin{array}{cccc}
\Delta_{o 1}(1) & \Delta_{o 1}(2) & \ldots . . & \Delta_{o 1}(m) \\
\Delta_{o 2}(1) & \Delta_{o 2}(2) & \ldots . . & \Delta_{o 2}(m) \\
\ldots \ldots . & \ldots \ldots \ldots & \ldots . & \ldots \ldots \ldots \\
\Delta_{o n}(1) & \Delta_{o n}(2) & \ldots . . & \Delta_{o n}(m)
\end{array}\right]
\end{aligned}
$$

Step 5: Calculate the grey relational coefficient.

$$
\gamma_{o i}(j)=\frac{\Delta_{\min }+\zeta \Delta_{\max }}{\Delta_{o i}(j)+\zeta \Delta_{\max }}
$$


where $\Delta_{\max }=\max _{i} \max _{j} \Delta_{o i}(j), \quad \Delta_{\min }=\min _{i} \min _{j} \Delta_{o i}(j)$ and $\zeta \in[0,1], \zeta$ is known as the distinguishing coefficient or the index for distinguishability. $\zeta, \Delta_{\max }$

It is used to eliminate the possibility that the extreme values in the data array and is usually taken 0,5 . Step 6: Calculate the grey relational degree. If the weights $\left(w_{i}\right)$ of criteria are determined, the degree of grey coefficient $\Gamma_{o i}$ is computed as:

$$
\Gamma_{o i}=\sum_{j=1}^{m}\left[w_{i}(j) * \gamma_{o i}(j)\right], \quad \sum_{j=1}^{m} w(j)=1
$$

\section{Application}

The Application part of the study consists of three phases. During the first phase, data sets of criteria for measuring performance of the airline web sites and information about the preparation of the data set are provided. In the second phase, the weights of criteria are calculated by the Entropy Weight Method and during the last phase, the performance of the website using the Grey Relational Analysis was provided decision support for decision makers.

\subsection{Preparation of Data Sets}

In the study, 23 criteria were identified for evaluating the performance of the website primarily. The number of criteria were reduced to 7 criteria by 4 experts. Experts experienced in software and web design who were computer engineers and web masters. The criteria were used in this study and their descriptions are as in Table 1.

\section{Table 1}

Website Performance Measurement Criteria

\begin{tabular}{|c|c|}
\hline Criteria & Definition \\
\hline C1 (Traffic) & $\begin{array}{l}\text { Browser collects data and the collected data transmitted to the website of the Alexa by } \\
\text { browser, where it is stored and analysed to form the basis for company's web traffic } \\
\text { reporting. }\end{array}$ \\
\hline C2 (Page Rank) & It is used to calculate and display the PageRank for each Website. \\
\hline C3 (Design Optimization) & $\begin{array}{l}\text { The scripts, HTML or CSS codes optimized for faster loading. The optimization also } \\
\text { reduces the number of website elements such as images, scripts, html, css codes or video. }\end{array}$ \\
\hline C4 (Load Time) & It is used to calculate the time required to load a page and its graphics. \\
\hline C5 (Response Time) & A Website server should respond to a browser request within certain parameters \\
\hline C6 (Markup) & $\begin{array}{l}\text { It is utilized to assess and calculate the number of HTML errors, which exist on the website, } \\
\text { such as orphan codes, coding errors, missing tags and etc. }\end{array}$ \\
\hline C7 (Broken Link) & $\begin{array}{l}\text { Broken links always reduces the quality of website. Websites has internal or external links. } \\
\text { A visitor expects the links to be valid, loads successfully to the clicked page. }\end{array}$ \\
\hline
\end{tabular}

Table 2 presents the list of all criteria and their website quality evaluation tools, which is examined in this study.

\section{Table 2}

Online Web- Diagnostic Tools for Data Collection

\begin{tabular}{ll}
\hline Quality Criteria & Online Web Diagnostic Tools \\
\hline Traffic & www.alexa.com \\
Page Rank & https://www.pagerank.net/pagerank-checker/ \\
Design Optimization & tools.pingdom.com \\
Load Time & tools.pingdom.com \\
Response Time & www.websiteoptimization.com \\
Mark Up & http://validator.w3.org/ \\
Broken Links & Xenu's Link Sleuth \\
\hline
\end{tabular}


The data in Table 1 was taken from more than 30 trails on various occasions on different periods of times to analyze the websites. This data has been taken from 12/1/2016 to 12/31/2016. Table 3 depicts the descriptive statistics of the data set.

Table 3

The Descriptive Statistics of the Data Sets

\begin{tabular}{lllll}
\hline Criteria & Mean & Std.Deviation & Max. & Min. \\
\hline C1 (Traffic) & 681507,5 & 1047681 & 3783241 & 2798 \\
C2 (Page Rank) & 4,448485 & 3,024532 & 8 & 0 \\
C3 (Des.Opt.) & 72,82121 & 10,36513 & 91 & 56 \\
C4 (Load Time) & 8,560088 & 10,36385 & 60,04 & 0,375 \\
C5 (Resp. Time) & 1,600864 & 1,237063 & 10,158 & 0,622 \\
C6 (Markup) & 80,38182 & 145,2519 & 517 & 0 \\
C7 (Brok. Link) & 24000,38 & 83405,78 & 784263 & 7 \\
\hline
\end{tabular}

\subsection{The determination of the weights of the criteria using the Entropy Weight method}

The weights of the criteria were determined by using the Entropy Weight Method in this study. Decision Matrix consists of the mean of 30 trails on various occasions on the different periods of times represented in Table 4. The website names are hidden for confidentiality and have been renamed WS1 to WS11.

Table 4

Decision Matrix

\begin{tabular}{llllllll}
\hline & C1 (Traffic) & C2 (Page Rank) & C3 (Des.Opt.) & C4 (Load Time) & C5 (Resp. Time) & C6 (Markup) & C7 (Brok. Link) \\
\hline WS1 & 2904,5667 & 8,0000 & 63,9333 & 10,7420 & 1,8763 & 5,6333 & 32053,13 \\
WS2 & 5504,9667 & 6,0000 & 80,4667 & 12,6230 & 3,8177 & 28,0000 & 2415,966 \\
WS3 & 28561,8667 & 7,0000 & 64,4667 & 27,6860 & 1,2184 & 94,8000 & 2052,466 \\
WS4 & 31053,8000 & 7,9333 & 63,0667 & 6,6250 & 3,4568 & 516,866 & 198508,0 \\
WS5 & 30551,3000 & 0,0000 & 69,6667 & 7,3137 & 1,1080 & 144,766 & 24546,60 \\
WS6 & 748724,200 & 0,0000 & 86,3333 & 2,5433 & 0,7954 & 0,0000 & 1039,000 \\
WS7 & 54084,1667 & 7,0000 & 64,5667 & 4,5913 & 0,7301 & 34,4000 & 2653,166 \\
WS8 & 127450,800 & 5,0000 & 89,7667 & 4,2433 & 1,5382 & 21,9000 & 488,8667 \\
WS9 & 3438669,300 & 0,0000 & 67,6667 & 4,9467 & 1,3050 & 16,0000 & 7,0000 \\
WS10 & 1342224,16 & 4,0000 & 68,7333 & 9,6857 & 0,7678 & 9,8333 & 104,0667 \\
WS11 & 1686853,16 & 4,0000 & 82,3667 & 3,1610 & 0,9959 & 12,0000 & 135,8333 \\
\hline
\end{tabular}

Decision matrix was normalized via Eq. (2) and the normalized decision matrix was obtained.

Table 5

Normalized Decision Matrix

\begin{tabular}{llllllll}
\hline & C1 (Traffic) & C2 (Page Rank) & C3 (Des.Opt.) & C4 (Load Time) & C5 (Resp. Time) & C6 (Markup) & C7 (Brok. Link) \\
\hline WS1 & 0,0004 & 0,1635 & 0,0798 & 0,1141 & 0,1066 & 0,0064 & 0,1214 \\
WS2 & 0,0007 & 0,1226 & 0,1005 & 0,1341 & 0,2168 & 0,0317 & 0,0092 \\
WS3 & 0,0038 & 0,1431 & 0,0805 & 0,2940 & 0,0692 & 0,1072 & 0,0078 \\
WS4 & 0,0041 & 0,1621 & 0,0787 & 0,0704 & 0,1963 & 0,5846 & 0,7519 \\
WS5 & 0,0041 & 0,0000 & 0,0870 & 0,0777 & 0,0629 & 0,1637 & 0,0930 \\
WS6 & 0,0999 & 0,0000 & 0,1078 & 0,0270 & 0,0452 & 0,0000 & 0,0039 \\
WS7 & 0,0072 & 0,1431 & 0,0806 & 0,0488 & 0,0415 & 0,0389 & 0,0100 \\
WS8 & 0,0170 & 0,1022 & 0,1121 & 0,0451 & 0,0873 & 0,0248 & 0,0019 \\
WS9 & 0,4587 & 0,0000 & 0,0845 & 0,0525 & 0,0741 & 0,0181 & 0,0000 \\
WS10 & 0,1790 & 0,0817 & 0,0858 & 0,1029 & 0,0436 & 0,0111 & 0,0004 \\
WS11 & 0,2250 & 0,0817 & 0,1028 & 0,0336 & 0,0566 & 0,0136 & 0,0005 \\
\hline
\end{tabular}


Entropy measurement of every index and degree of divergence was calculated by using Eqs. (4-6). Finally, the objective weight for each criterion was calculated.

Table 6

The Objective Weight $\left(W_{j}\right)$ for Each Criterion

\begin{tabular}{lllllllll}
\hline ej & 0,5883 & 0,8537 & 0,9966 & 0,8964 & 0,9280 & 0,5797 & 0,3582 & \\
dj & 0,4117 & 0,1463 & 0,0034 & 0,1036 & 0,0720 & 0,4203 & 0,6418 & $\sum d_{j} 1,7992$ \\
& & & & & & & & \\
wj & $\mathbf{0 , 2 2 8 8}$ & $\mathbf{0 , 0 8 1 3}$ & $\mathbf{0 , 0 0 1 9}$ & $\mathbf{0 , 0 5 7 6}$ & $\mathbf{0 , 0 4 0 0}$ & $\mathbf{0 , 2 3 3 6}$ & $\mathbf{0 , 3 5 6 7}$ & \\
\hline
\end{tabular}

\subsection{Performance evaluation with grey relational analysis}

The weights of criteria were calculated by using the Entropy Weight Method and then ranked the performance of the web sites via Grey Relational Analysis. In the first phase, decision matrix was normalized in Table 4. Traffic, page rank and design optimization are measured based on the larger the better; load time, response time, markup validation and broken link are considered based on the smaller the better. Normalization process was carried out by using the Eqs. (8-9).

Table 7

Normalized Comparison Series

\begin{tabular}{llllllll}
\hline & $\begin{array}{l}\text { C1 } \\
\text { (Traffic) }\end{array}$ & $\begin{array}{l}\text { C2 (Page } \\
\text { Rank) }\end{array}$ & $\begin{array}{l}\text { C3 } \\
\text { (Des.Opt.) }\end{array}$ & $\begin{array}{l}\text { C4 (Load } \\
\text { Time) }\end{array}$ & $\begin{array}{l}\text { C5 (Resp. } \\
\text { Time) }\end{array}$ & $\begin{array}{l}\text { C6 } \\
\text { (Markup) }\end{array}$ & $\begin{array}{l}\text { C7 (Brok. } \\
\text { Link) }\end{array}$ \\
\hline X (Reference Value) & 1,00 & 1,00 & 1,00 & 1,00 & 1,00 & 1,00 & 1,00 \\
WS1 & 0,0000 & 1,0000 & 0,0325 & 0,6739 & 0,6288 & 0,9891 & 0,8386 \\
WS2 & 0,0008 & 0,7500 & 0,6517 & 0,5991 & 0,0000 & 0,9458 & 0,9879 \\
WS3 & 0,0075 & 0,8750 & 0,0524 & 0,0000 & 0,8418 & 0,8166 & 0,9897 \\
WS4 & 0,0082 & 0,9917 & 0,0000 & 0,8377 & 0,1169 & 0,0000 & 0,0000 \\
WS5 & 0,0080 & 0,0000 & 0,2472 & 0,8103 & 0,8776 & 0,7199 & 0,8764 \\
WS6 & 0,2171 & 0,0000 & 0,8714 & 1,0000 & 0,9789 & 1,0000 & 0,9948 \\
WS7 & 0,0149 & 0,8750 & 0,0562 & 0,9185 & 1,0000 & 0,9334 & 0,9867 \\
WS8 & 0,0362 & 0,6250 & 1,0000 & 0,9324 & 0,7383 & 0,9576 & 0,9976 \\
WS9 & 1,0000 & 0,0000 & 0,1723 & 0,9044 & 0,8138 & 0,9690 & 1,0000 \\
WS10 & 0,3898 & 0,5000 & 0,2122 & 0,7159 & 0,9878 & 0,9810 & 0,9995 \\
WS11 & 0,4901 & 0,5000 & 0,7228 & 0,9754 & 0,9139 & 0,9768 & 0,9994 \\
\hline
\end{tabular}

The Distance between the normalized criteria values and the reference set was measured by Eq. (12) and the absolute value matrix was constituted.

Table 8

Absolute Value Matrix

\begin{tabular}{lccccccc}
\hline & C1 (Traffic) & C2 (Page Rank) & C3 (Des.Opt.) & C4 (Load Time) & C5 (Resp. Time) & C6 (Markup) & C7 (Brok. Link) \\
\hline X & 1,00 & 1,00 & 1,00 & 1,00 & 1,00 & 1,00 & 1,00 \\
WS1 & 1,0000 & 0,0000 & 0,9675 & 0,3261 & 0,3712 & 0,0109 & 0,1614 \\
WS2 & 0,9992 & 0,2500 & 0,3483 & 0,4009 & 1,0000 & 0,0542 & 0,0121 \\
WS3 & 0,9925 & 0,1250 & 0,9476 & 1,0000 & 0,1582 & 0,1834 & 0,0103 \\
WS4 & 0,9918 & 0,0083 & 1,0000 & 0,1623 & 0,8831 & 1,0000 & 1,0000 \\
WS5 & 0,9920 & 1,0000 & 0,7528 & 0,1897 & 0,1224 & 0,2801 & 0,1236 \\
WS6 & 0,7829 & 1,0000 & 0,1286 & 0,0000 & 0,0211 & 0,0000 & 0,0052 \\
WS7 & 0,9851 & 0,1250 & 0,9438 & 0,0815 & 0,0000 & 0,0666 & 0,0133 \\
WS8 & 0,9638 & 0,3750 & 0,0000 & 0,0676 & 0,2617 & 0,0424 & 0,0024 \\
WS9 & 0,0000 & 1,0000 & 0,8277 & 0,0956 & 0,1862 & 0,0310 & 0,0000 \\
WS10 & 0,6102 & 0,5000 & 0,7878 & 0,2841 & 0,0122 & 0,0190 & 0,0005 \\
WS11 & 0,5099 & 0,5000 & 0,2772 & 0,0246 & 0,0861 & 0,0232 & 0,0006 \\
\hline
\end{tabular}


Grey relational coefficients were calculated by using Eq. (14).

Table 9

Grey Relational Coefficients

\begin{tabular}{llllllll}
\hline & C1 (Traffic) & C2 (Page Rank) & C3 (Des.Opt.) & C4 (Load Time) & C5 (Resp. Time) & C6 (Markup) & C7 (Brok. Link) \\
\hline WS1 & 0,3333 & 1,0000 & 0,3407 & 0,6053 & 0,5739 & 0,9787 & 0,7559 \\
WS2 & 0,3335 & 0,6667 & 0,5894 & 0,5550 & 0,3333 & 0,9022 & 0,9763 \\
WS3 & 0,3350 & 0,8000 & 0,3454 & 0,3333 & 0,7597 & 0,7316 & 0,9798 \\
WS4 & 0,3352 & 0,9836 & 0,3333 & 0,7549 & 0,3615 & 0,3333 & 0,3333 \\
WS5 & 0,3351 & 0,3333 & 0,3991 & 0,7249 & 0,8034 & 0,6410 & 0,8018 \\
WS6 & 0,3897 & 0,3333 & 0,7954 & 1,0000 & 0,9594 & 1,0000 & 0,9897 \\
WS7 & 0,3367 & 0,8000 & 0,3463 & 0,8599 & 1,0000 & 0,8825 & 0,9740 \\
WS8 & 0,3416 & 0,5714 & 1,0000 & 0,8809 & 0,6564 & 0,9219 & 0,9952 \\
WS9 & 1,0000 & 0,3333 & 0,3766 & 0,8395 & 0,7287 & 0,9417 & 1,0000 \\
WS10 & 0,4504 & 0,5000 & 0,3883 & 0,6377 & 0,9762 & 0,9633 & 0,9990 \\
WS11 & 0,4951 & 0,5000 & 0,6434 & 0,9532 & 0,8531 & 0,9556 & 0,9987 \\
\hline
\end{tabular}

As a result, grey relational degrees were calculated by using Eq. (15). These criteria in Table 5 were used for the weight of each criteria calculated by the Entropy Weight Method. Table 10 depicts the proposed Entropy Weight Method and Grey Relational Analysis model performance scores and ranks the airline websites.

Table 10

The performance score and ranking of the Websites

\begin{tabular}{lll}
\hline & Performance Score & Ranked Data \\
\hline WS1 & 0,7144 & 8 \\
WS2 & 0,7360 & 7 \\
WS3 & 0,7124 & 9 \\
WS4 & 0,4120 & 11 \\
WS5 & 0,6142 & 10 \\
WS6 & 0,8005 & 4 \\
WS7 & 0,7859 & 5 \\
WS8 & 0,7739 & 6 \\
WS9 & 0,9109 & 1 \\
WS10 & 0,8017 & 3 \\
WS11 & 0,8237 & 2 \\
\hline
\end{tabular}

\section{Conclusion}

In this paper, we have proposed a hybrid model to combine Entropy Weight Method and Grey Relational Analysis for determining and evaluating the quality of airline websites with the sample of eleven airline websites. We have assessed many dimensions of quality and each dimension was measured by using online diagnostic tools. The result of this study endorsed that the performance and the quality criteria were neglected by the the airlines websites. The airline industry adopts advanced ecommerce technologies to keep their loyal customers and attract new passengers, but it is likely that not all airlines' administrator have well-defined knowledge about how many gaps should be filled between the usual and a perfect website. According to our research; airline companies make more effort to meet these criteria in the context of website design. Airline websites should follow and encourage the use of recognised guidelines when designing website, this suggestion is responsible for web developers. To get results on the quality of in the context of Turkish airline's website, we have assessed sample data from airline websites and calculated traffic, page rank, design optimization, load time, response time, mark up and broken links. The proposed model has been implemented using Entropy Weight Method and Grey Relational Analysis. This research has some limititations, which arose in the 
number of the sample size and time factor, this research used the limited sample size 30 data and it was taken during short period observation time.

The future aims for this work are added criteria for assessing the performance and the quality of websites, such as privacy, availability, color scheme, security and browser compatibility problem. In addition, the supreme determining factor of the quality of the website is the users, the future aims for this study also encompasses the user's perspective, which contains the objective and subjective views of the website. The Future research includes adding more criteria to measure the website performance. As the airline industry is highly rich information based industry and has a great amount of usergenerated travel content, the future research should be done with the context of customer satisfaction. A theoretical framework needs to be developed which identifies the factors that measure the customer satisfaction, reputation, profitability, financial performance and loyalty with airline websites.

In addition on the grounds that a definitive determinant of the quality site is the clients, the future headings for this exploration likewise includes the target and subjective perspectives of the site from the client's point of view.

\section{References}

Chang, D. Y. (1996). Applications of the extent analysis method on fuzzy AHP. European Journal of Operational Research, 95(3), 649-655.

Deng, H., Yeh, C. H., \& Willis, R. J. (2000). Inter-company comparison using modified TOPSIS with objective weights. Computers \& Operations Research, 27(10), 963-973.

Dominic, P. D. D., \& Jati, H. (2011). A comparison of Asian airlines websites quality: using a nonparametric test. International Journal of Business Innovation and Research, 5(5), 599-623.

Fontela, E., \& Gabus, A. The DEMATEL Observer. 1976. Battelle Institute, Geneva Research Center.

Hidalgo, L., Cabrerizo, F.J., López Gijón, J., Herrera-Viedma, E. (2007). Applying Fuzzy linguistic Tools to Evaluate the Quality of Airline Web Sites. In Proceedings of the II Congreso Español de Informática (CEDI 2007). II Simposio sobre Lógica Fuzzy and Soft Computing (LFSC 2007), $113-$ 119

Jati, H. (2009). Performance measurement evaluation on quality of Asian Airlines websites: An ANP approach. 4th Intnerational Conference on E-Commerce with focus on developing countries.

Khan, H., \& Dominic, P. D. D. (2013). Measuring Quality of Asian Airline Websites Using Analytical Hierarchy Process: A Future Customer Satisfaction Approach. ISICO 2013.

Lee, Y., \& Kozar, K. A. (2006). Investigating the effect of website quality on e-business success: An analytic hierarchy process (AHP) approach. Decision support systems, 42(3), 1383-1401.

Li, X., Wang, K., Liu, L., Xin, J., Yang, H., \& Gao, C. (2011). Application of the entropy weight and TOPSIS method in safety evaluation of coal mines. Procedia Engineering, 26, 2085-2091.

Lu, I. J., Lin, S. J., \& Lewis, C. (2008). Grey relation analysis of motor vehicular energy consumption in Taiwan. Energy Policy, 36(7), 2556-2561.

Opricovic, S., \& Tzeng, G. H. (2004). Compromise solution by MCDM methods: A comparative analysis of VIKOR and TOPSIS. European journal of operational research, 156(2), 445-455.

Phippen, A., Sheppard, L., \& Furnell, S. (2004). A practical evaluation of Web analytics. Internet Research, 14(4), 284-293.

Saaty, T. L. (1980). The analytic hierarchy process: planning, priority setting, resource allocation. McGraw-Hill International Book Company.

Saaty, T. L. (1996). Decision making with dependence and feedback: The analytic network process (Vol. 4922). Pittsburgh: RWS publications.

Senthilkumar, N., Tamizharasan, T., \& Anandakrishnan, V. (2014). Experimental investigation and performance analysis of cemented carbide inserts of different geometries using Taguchi based grey relational analysis. Measurement, 58, 520-536. 
Shemshadi, A., Shirazi, H., Toreihi, M., \& Tarokh, M. J. (2011). A fuzzy VIKOR method for supplier selection based on entropy measure for objective weighting. Expert Systems with Applications, 38(10), 12160-12167.

Tsai, W.H., Leu, J.D. and Chou, W.C. (2009). The Development of an Evaluation Model of ECommerce Websites for the Taiwanese Airline Industry. In S. Newell, E. A. Whitley, N. Pouloudi, J. Wareham \& L. Mathiassen (eds.), 170-181

Tsai, W. H., Chou, W. C., \& Leu, J. D. (2011). An effectiveness evaluation model for the web-based marketing of the airline industry. Expert Systems with Applications, 38(12), 15499-15516.

Wang, Y. J. (2008). Applying FMCDM to evaluate financial performance of domestic airlines in Taiwan. Expert Systems with Applications, 34(3), 1837-1845.

$\mathrm{Wu}, \mathrm{H}$. H. (2002). A comparative study of using grey relational analysis in multiple attribute decision making problems. Quality Engineering, 15(2), 209-217.

Wu, J., Sun, J., Liang, L., \& Zha, Y. (2011). Determination of weights for ultimate cross efficiency using Shannon entropy. Expert Systems with Applications, 38(5), 5162-5165.

$\mathrm{Wu}, \mathrm{W} . \mathrm{W} .$, \& Lee, Y. T. (2007). Developing global managers' competencies using the fuzzy DEMATEL method. Expert systems with applications, 32(2), 499-507.

Zhai, L. Y., Khoo, L. P., \& Zhong, Z. W. (2009). Design concept evaluation in product development using rough sets and grey relation analysis. Expert Systems with Applications, 36(3), 7072-7079.

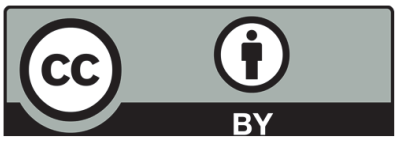

(C) 2018 by the authors; licensee Growing Science, Canada. This is an open access article distributed under the terms and conditions of the Creative Commons Attribution (CC-BY) license (http://creativecommons.org/licenses/by/4.0/). 